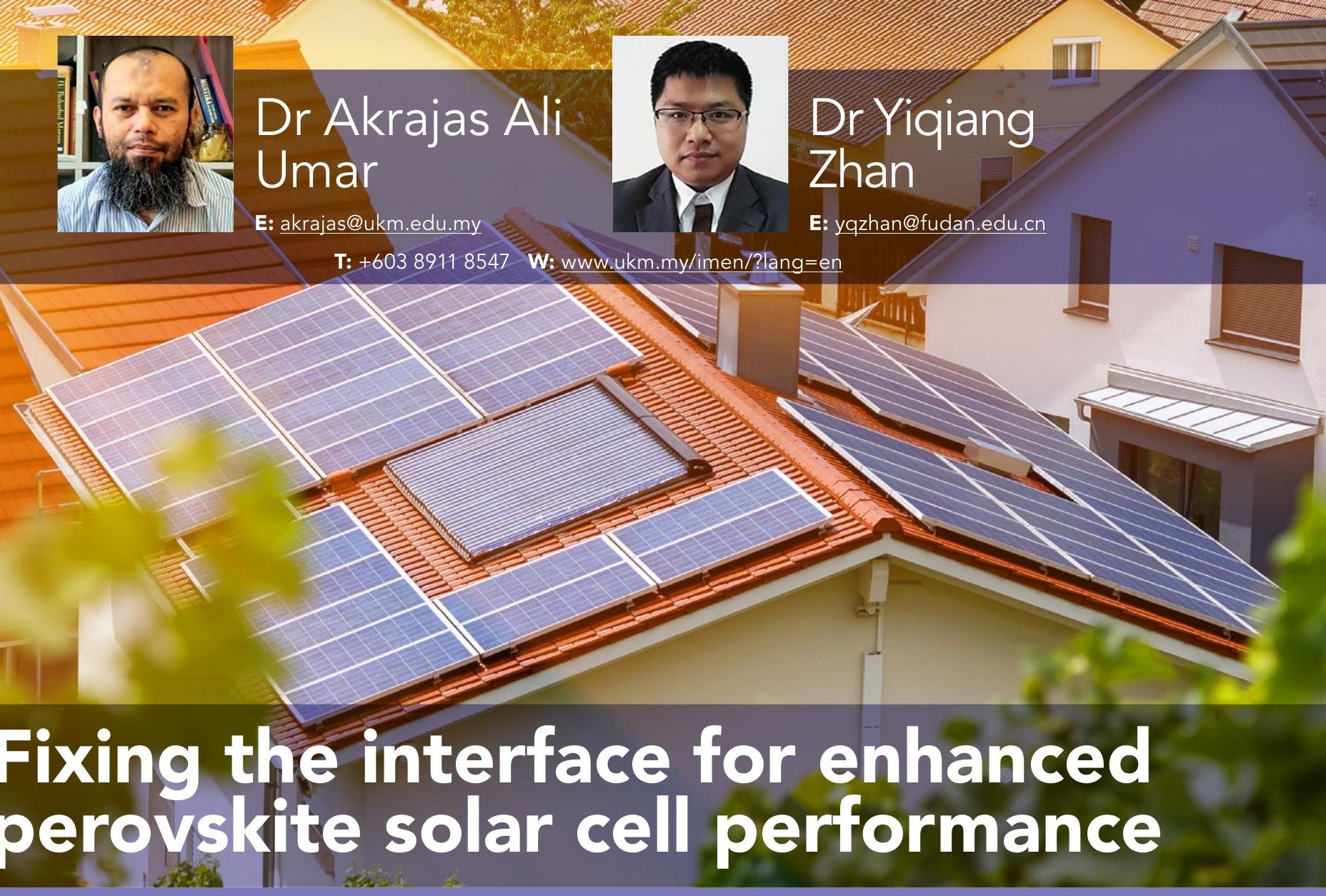

\section{Research Objectives}

The physics and chemistry of nanomaterials and their applications for energy conversion.

\section{References}

- Kojima, A., et al. (2009). Organometal Halide Perovskites as Visible-Light Sensitizers for Photovoltaic Cells. Journal of the American Chemical Society. 131 (17): 6050-6051.

- United Nations (2015). Ensure access to affordable, reliable, sustainable and modern energy. [online] un.org. Available at: www.un.org/sustainabledevelopment/energy [Accessed 21 June 2021].

- Manser, J., et al. (2016) Intriguing Optoelectronic Properties of Metal Halide Perovskites. Chemical Reviews, 116(21), 12956-13008.

- Creutzig, F., et al. (2017) The underestimated potential of solar energy to mitigate climate change. Nature Energy, 2, 17140.

- Kerr, Emily. (2019) The Future of Solar is Bright. [online] Harvard University Blog. Available at: sitn.hms.harvard.edu/flash/2019/ future-solar-bright [Accessed 21 June 2021].

- The World Bank. (2020) Solar Photovoltaic Power Potential by Country. [online] The World Bank. Available at: www.worldbank. org/en/topic/energy/publication/solar-photovoltaic-powerpotential-by-country [Accessed 21 June 2021]

- Alias, N., et al. (2021) Photoelectrical Dynamics Uplift in Perovskite Solar Cells by Atoms Thick 2D TiS 2 Layer Passivation of $\mathrm{TiO}_{2}$ Nanograss Electron Transport Layer. ACS Applied Materials \& Interfaces, 13, 3051-3061.
Detail

Institute of Microengineering and Nanoelectronics, Universiti Kebangsaan Malaysia, 43600 UKM Bangi, Selangor, Malaysia.

\section{Bio}

Dr Akrajas Ali Umar gained his PhD in Physics from Universiti Kebangsaan Malaysia in 2004. He is currently Associate Professor in the Institute of Microengineering and Nanoelectronics (IMEN), Universiti Kebangsaan Malaysia since 2011. His research interests are the physics and chemistry of nanomaterials with the emphasis on energy conversion application

Professor Dr Yiqiang Zhan obtained his PhD in Condensed Matter Physics in 2005 from Fudan University, Shanghai, P.R. China, where is currently based. His research focuses on the realisation of high-performance and high stability perovskite solar cells by interface and structural effect control of the photoactive component in solar cells.

\section{Funding}

Ministry of Higher Education, Malaysia, research grant no FRGS/1/2019/STG02/UKM/02/03. Shanghai Science and Technology Innovation Action Plan, Belt \& Road Young Scientist Program (grant no.17160742900). National Natural Science Foundation of China (grant no. 61774046).

\section{Personal Response}

\section{How do you hope your work will contribute to the availability} of electricity worldwide?

II Our finding is expected to solve the deficiency in the photocarrier dynamic at the interface between electron transport layer and perovskite because of defects. Defects passivation will generate facile carrier dynamic at the interface, improving the performance and the stability of the perovskite solar cells. This is expected to accelerate the real application of the perovskite solar cells to contribute to the availability of electricity worldwide. 
Engineering \& Technology | Akrajas Ali Umar \& Yiqiang Zhan

\section{Fixing the interface for enhanced perovskite solar cell performance}

With millions of people in the world still having no access to electricity, it is easy to predict that the world's already challenging energy demands will only increase. Solar power has long presented itself as a promising renewable energy source, but the solar cells used in photovoltaics still suffer from relatively low efficiency, even when novel materials such as perovskites are employed. Dr Akrajas Ali Umar, of the Universiti Kebangsaan Malaysia, and Professor Yiqiang Zhan of Fudan University, China, have reported on in the electron transport material of perovskites solar cells, leading to a

Electricity is a basic requirement for

heating, water extraction systems, and the many other small appliances that are essential to raise people above the poverty line. Yet the United Nation (UN) estimates that there are still 789 million people around the world with no access to electricity. While it is crucial to make electricity available and accessible to everyone, the energy sector is the largest contributor to the greenhouse gas emissions responsible for clim resulting from burning fossil fuels to the

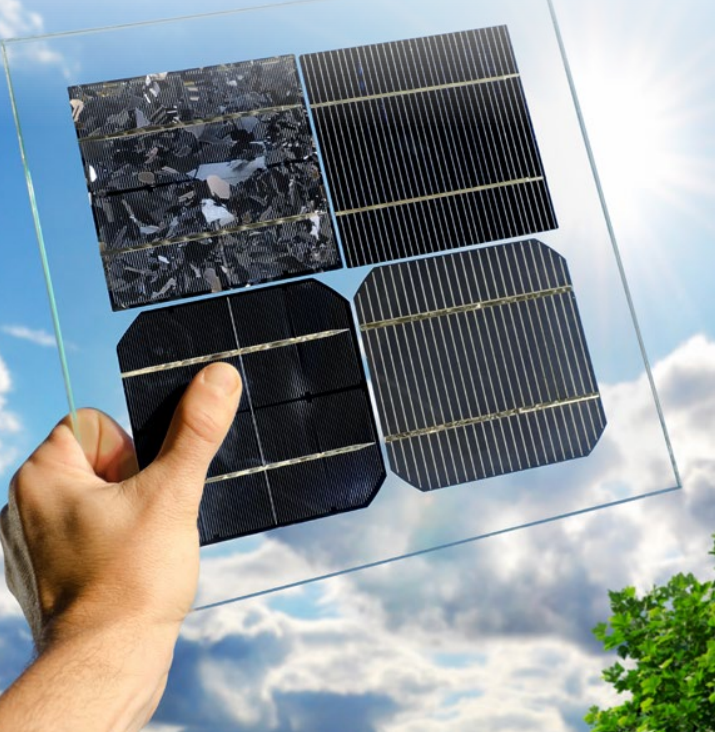

methane released by extracting and burning natural gas, our need for energy is at the heart of a warming planet. It is zero energy poverty are driven by sustainable and environmentally friendly technologies, a statement that forms the basis of goal number 7 of the UN's 7 sustainable development goals.

Solar power is a promising option in our quest to find more sustainable sources of energy. Every second, the hours of the Earth's enorgy to fuel two hours of the Earhs energy demands at the global population live in 70 countries that have high potential for harnessing solar power, and some of them could do so without experiencing any seasonaldrops in output. It has been estimated that, with proper investment in the necessary technology, solar power could generate $30-50 \%$
electricity needs.

\section{THE SOLAR CHALLENGE}

Historically, the problem with harvesting the immense power of the Sun for generating electricity has been the cost and relative inefficiency of solar power technology. Even though the amount of power collected globally from sol energy increased more than 300-fold
between 2000 to 2019 , the efficiency of photovoltaics - how much sunligh can effectively be turned into electricity - remains a challenge for the continued growth of solar power.

Traditionally, the solar cells needed to convert sunlight into electricity were ach $25 \%$. When silicon is combined with other semiconductor materials, creating what is called a multi-iunction solar cell, this efficiency can be increased

to approximately $30 \%$. But this is still relatively low, and achieving the enormous potential of solar power will require new efforts towards improving the performance of solar cells. As such, further advances in solar power technology will necessarily include finding new materials that can be used in high efficiency solar cells.

\section{PEROVSKITE GROWTH} AND PROMISE

Pollat materials attention since their first successful incorporation into a solar cell in 2009. Specifically, a perovskite is a calcium titanium oxide mineral, but other materials with similar structures are also referred to as perovskites. The perovskite materials most commonly employed in solar cells are hybrid lead or tin halide-based materials which tend to be both cheap to produce and simple to manufacture. Having started with an efficiency of less than $4 \%$ when they were first invented, perovskite solar cells can now achieve efficiencies of $25 \%$ on their own or $30 \%$ when combined with silicon in multi-junction solar cells. In addition, the photoelectrical properties by carefullly selecting the metals that by carefuly selecting the metals that

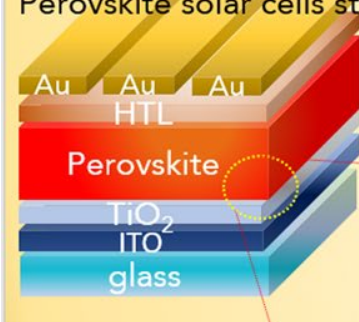

Perovskite-TiO2 (ETL) Interface

The researchers used an atomically-thin
wo-dimensional layer of titanium sulphid

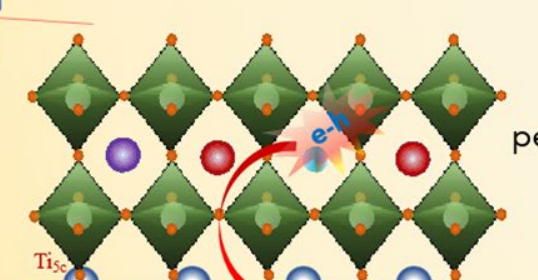

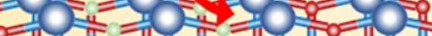

$O=T i$
$0=0$

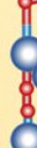
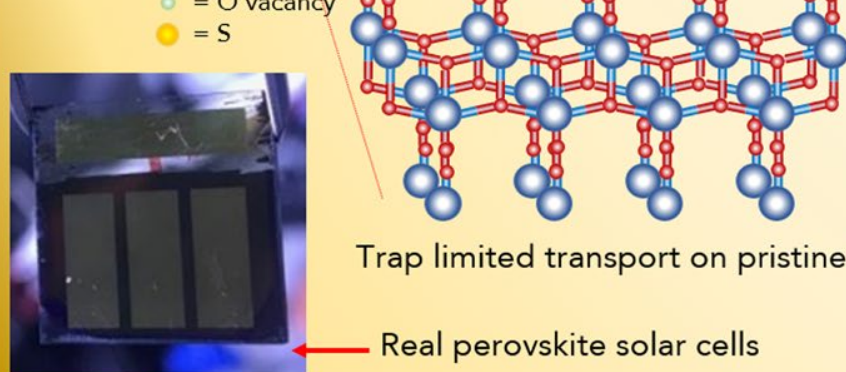

$\mathrm{TiS}_{2}$

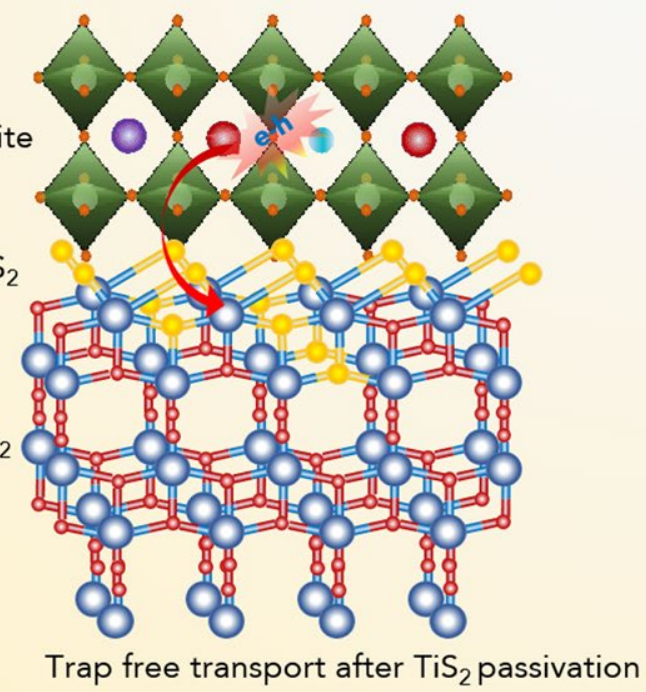

Trap limited transort on pristine $\mathrm{TiO}_{2}$

Trap free transort after TiS passivation

Despite their fast development, the efficiency of perovskite solar cells still needs to be improved further. One of the key places of a perovskite solar cell where efficiency is lost is at the interface en transport layer of the cell and the perovskite materia itself, where electrons are exchanged between the two parts. Any defects in the electron transport layer will trap the perovskite, and impede them from moving through the
solar cell as they solar cell as they

It has been estimated that, with

Yiqiang Zhan of Fudan University in China, have recently reported on the enhancement of the photoelectrical dynamic of perovskite solar cells by passivation of their titanium dioxide
$(\mathrm{TiO})$ electron transport layer. The researchers used an atomically thin two-dimensional (2D) layer of titaniu sulphide $\left(\mathrm{TiS}_{2}\right)$ as a passivation sulphur material, and found proper investment, solar power could nable unimpeded through the solar

through the solar
cell, and therefore

to improve its efficiency, the defects on the electron transport layer need to be corrected. This defect correction, referred to as 'passivation', is usually achieved by adding layers of other materials that can cover the defects and thus improve the photoelectrical dynamic, ie. the movement of electrons, the interface between the perovskite FIX THE INTERFACE,

DIX

DrAkrajas Ali Umar of the Universiti

required globally.

oxygen $(\mathrm{O})$ vacancies in the electron transport layer, therefore leading to sivation. In addition, the conduction band of $\mathrm{TiS}_{2}$ is similar in energy to that of $\mathrm{TiO}_{2}$, which leads to a better coupling between the two materials. These ideal photoelectric properties of $\mathrm{TiS}_{2}$ were found to entogenerated electron tre perovskite and the open-circuit voltayer, mproving the open-circuit voltage and ultimately leading to nor

\section{UPLIFT IN}

PHOTOELECTRICAL DYNAMICS Notably, the researchers discovered that the $2 \mathrm{D} \mathrm{TiS}$, passivation layer the perovskite to the electron transport layer, and charge transportation from perovskite to the cathode, by ten times. It also boosted the carrier mobility in the solar cell by a factor of 1000, as ing the cell's stability. Devices containing solar cells with this new material were also found to retain during long periods of continuous operation under solar irradiation.

The researchers believe that this echnique - applying only an atoms-thick layer of a passivation material carefully selected to match core perovskite significant improvement in the efficiency of solar cells. Further optimisation of the passivation material, in particular with respect to the composition and structure of its crystal matrix, could further improve the efficiencies seen in this study. This is the focus of the research toam's current work and they expect to report on further in 


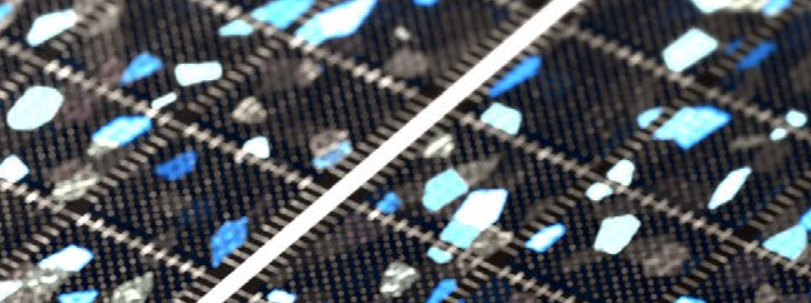

(1)

(I)

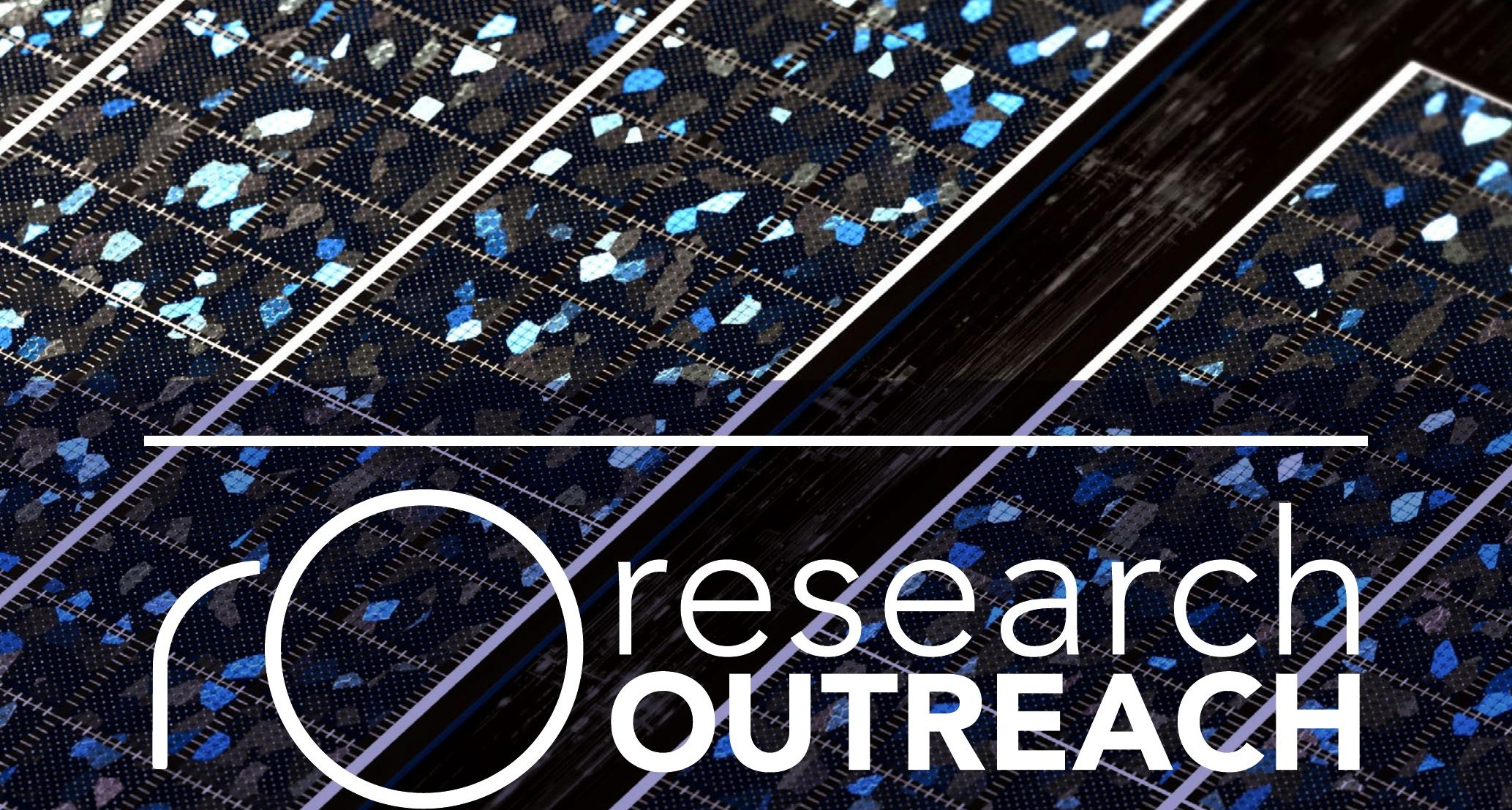

The public outreach magazine for the research community

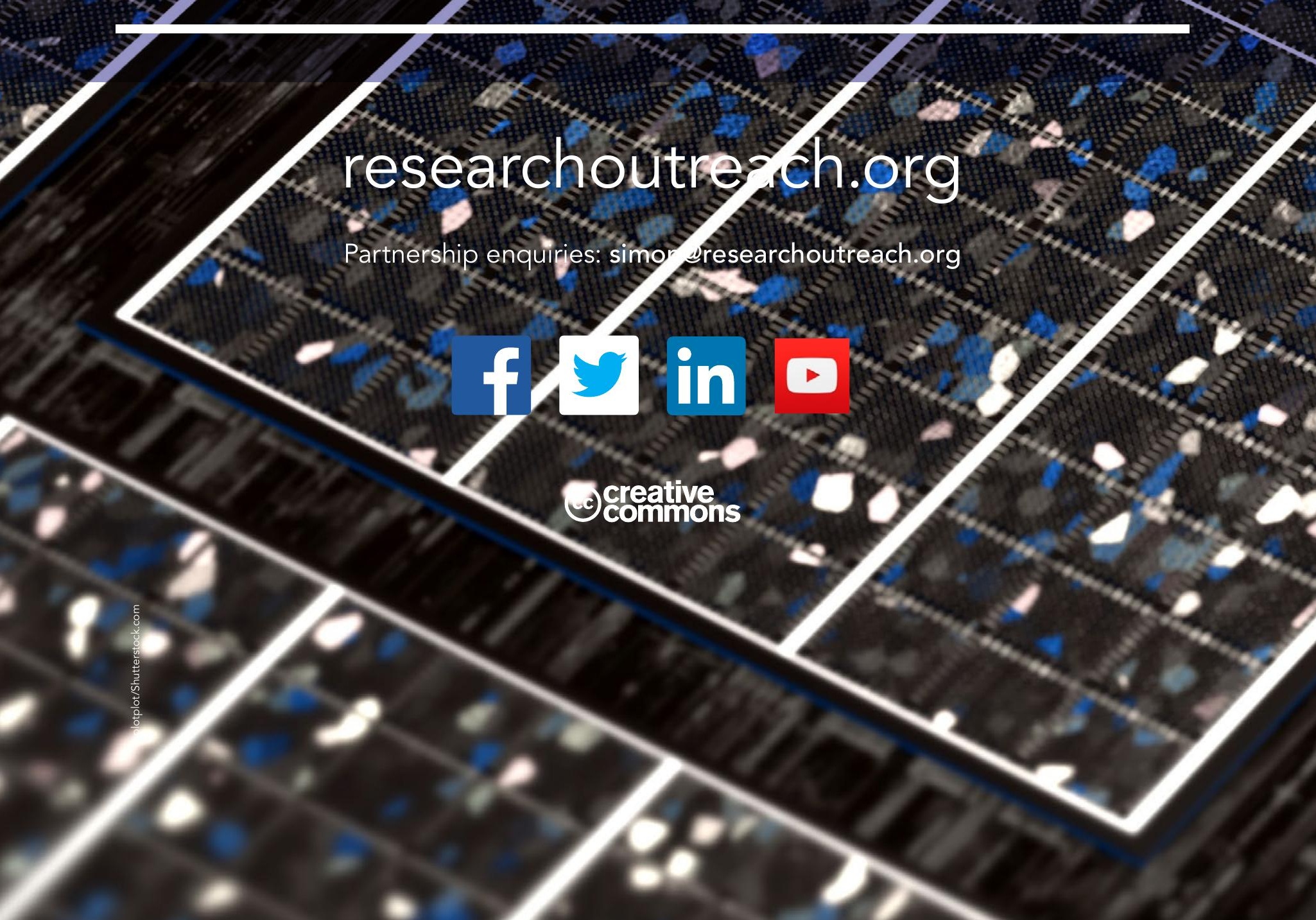

